IJMPB

12,1

104

\title{
INTERVIEW The (enlightened) perspective of an anthropologist on entrepreneurship and the project An interview with Jean-Pierre Boutinet
}

Jean-Pierre Boutinet is the author of Anthropologie du projet (2012) and Vers une société des agendas, Une mutation des temporalités (2004). The main focus of his work has been on the study of the project through the lens of his expertise as psychologist and anthropologist. This interview is quite relevant to project studies as it nurtures new thoughts on the relationship between entrepreneurship and projects. Boutinet influences in France on the understanding of the emergence and evolution of the word and the concept of project in the Western world has been tremendous. From this perspective, he offers a fresh critical look at the very central notion of time in the context of the project. He questions how the term project is used today and how we tend to dismiss the essence of its very nature for its creativity and meaning. As his work has been published only in French, it has not been discovered by the project management community at large with the exception of a few scholars (e.g. Garel, 2013; Scranton, 2015). We hence take the opportunity provided by this special section to introduce the important hidden elements of project studies to a larger audience. In short, we believe that Jean-Pierre Boutinet's unique perspective enlightens the relationship between entrepreneurship and the project.

The format of an interview facilitates a dialogue between these two fields. It allows to critically assess the links between the project approach and that of entrepreneurship in a natural conversation. The interview also situates the notions of entrepreneurship and the project in relation to each other, in their convergence and contrast. The figures of the entrepreneurship and the project are likely to bring creativity and singularity together.

Overall, we would like to know more about how Jean-Pierre Boutinet as a psychologist and anthropologist situates and compares the two notions of entrepreneurship and the project, and about the form which a dialogue between these two notions might take, ideally. The interview is organized in seven sections: convergences between entrepreneurship and the project; convergences between temporalities of entrepreneurship and the project; entrepreneurship, bricolage, improvisation and creativity; entrepreneurship and project management; about the entrepreneurial project: project to be completed and interminable project; space and time in the entrepreneurial project; and from the author of the project to the self-employed person, through the injunction to autonomy.

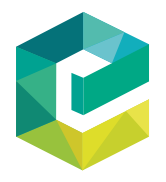

International Journal of Managing Projects in Business Vol. 12 No. 1,2019 pp. 104-113 (C) Emerald Publishing Limite $1753-8378$ DOI 10.1108/IJMPB-03-2019-216

\section{Convergences between entrepreneurship and the project}

I: What is your critical view of entrepreneurship and the project?

JPB: spontaneously, if I had to say something about the existing relationship between entrepreneurship and the project, I would say that I see a great similarity between these two figures insofar as both are creative processes that solicit the individual or collective actor's capacity to afford themselves the means of producing some novel form or other of technico-social

This article forms part of a special section "Exploring processual and critical avenues at the crossroad of entrepreneurship and project management", guest edited by Olivier Germain and Monique Aubry. 
or industrial entrepreneurship, or else some other original achievement. In fact, entrepreneurship constitutes a variant of the project; it is a creative process within an organization. However, entrepreneurship is at odds with two other variants of the project, with which it is not to be confused: the enterprise project (understood to include both for-profit enterprises and non-profit organizations) on the one hand, and project(-based) management on the other.

The enterprise project is characterized by its strong identity-oriented connotations. It is what we could call a benchmark or standard project, insofar as it sets out the values and goals that the stakeholders of the company or non-profit organization subscribe to and cultivate. The enterprise or non-profit organization's charter and logo are examples of the sorts of markers through which the stakeholders identify themselves and recognize their organization. This benchmark project may be combined with an operational or strategic project, initiated by management and outlining the organization's political orientation over one or more years; an orientation that members of the organization are then expected to adhere to.

The practice of project(-based) management, for its part, has expanded significantly over the course of the last half century in the organizational fields. It is defined in comparison to both the enterprise project, which anticipates a desired future around values shared by the enterprise collective, and the strategic project, which anticipates the development of the enterprise over the medium term. In contrast to these two figures, project(-based) management is intended as a presentist project, framed by the triple imperative imposed on every project manager or project engineer to control costs, deadlines and quality. In this type of management, the organization's management entrusts a mission to a team that has been chosen internally, solicited externally or composed from a mix of internal and external participants. This mission is framed by the triple requirement that we have just mentioned and constrained by the short-term perspective of a few months or the slightly longer term perspectives ranging from one to two years, or even more for major infrastructure projects.

Relative to the three figures of enterprise project, strategic project and project(-based) management, we can observe that the entrepreneurial project is a more recent figure, going back only about one generation. Within the projects found in organizations, it comprises a fourth figure that is composed of a process that is more open and much less formalized than the first three figures. Entrepreneurship involving either an individual actor or a collective of actors is deliberately conceived as a long-term process preferring to the near future, the most distant days. This entrepreneurship aims to develop and/or refurbish through a continuous process of evaluating the outcomes already achieved in order to reformulate priorities for new achievements. This is done in regards to the organization's general objectives, the results already achieved and the current state of the conjuncture. As a result, we find that the entrepreneurial project, in its exploration of a world of new possibilities, has the self-imposed mandate to provide creativity, whereas project(-based) management must remain focused on seeking the efficiencies cost, deadline and quality that are constitutive of its mandate. It should be remembered that the strategic project pursues the objective of maintaining and developing the organization, while the enterprise project is more sensitive to a search for legitimacy and consensus between the actors and project stakeholders.

\section{Convergences between temporalities of entrepreneurship and the project}

I: we thought it might be interesting to gather up the different notions of entrepreneurship and the project, to spur a dialogue on the question of temporality. The question we might ask is whether entrepreneurship and the project are articulated according to clearly distinct temporalities, or whether these notions are associated with two divergent temporalities.

JPB: entrepreneurship and the project both obey temporalities that tend to bracket the retrospective temporalities of memory in order to privilege the immediacy of the present moment, in particular those when the entrepreneur diagnoses the situation he is confronted 
IJMPB

12,1

\section{6}

with in his desire to "undertake" (entreprendre) and where he anticipates the future that is still to come in the following three ways:

(1) cognitive anticipations, working through foresight to inventory the world of possibilities available, here, in the field of entrepreneurship;

(2) adaptive anticipations, which are concerned with identifying probable, provisional futures, all other things being equal; and

(3) operational anticipations that are concretized in the elaboration of projects, relayed by the determination of categorical objectives, in order to profile an initiative to be implemented in the more or less short term.

While the temporalities of entrepreneurship tend to blend into those of the project, given that entrepreneurship is only a variant of the project, it should be noted that they are nevertheless to be distinguished from the particular temporality of project management which, given the overuse of organizational innovation practices, has evolved toward a formalism centered solely on the presentist temporalities of deadlines and short-term thinking. The temporalities of the entrepreneurial project are, on the contrary, open to still operational futures, bound by yet-to-be-determined reference points and already stated/yet-to-be articulated objectives. The temporalities of project management, for their part, are over-determined by the present time of deadlines that must be respected.

I: Indeed, in entrepreneurship and in project, do we conceive of the past, the present the future in a similar way?

JPB: in entrepreneurship, the past tends to be bracketed; only the present moment is at issue in the situational diagnostic that asks: What can I do given where I am, given this set of possibilities and constraints, and with the means at my disposal and looking toward a future that is still to be decoded and delineated by the potentialities it conceals, including those that I, the author, would like to bring about?

Although entrepreneurship has this sort of presentist connotation that is determined by the process that is to be encouraged and supported, that process nevertheless remains inseparable from the glimpse of the future toward which it is oriented. As a result, entrepreneurship does not lock itself into the present moment but opens out onto the future, given that "undertaking" (entreprendre) remains a complex operation that cannot be reduced to the immediacy of the moment.

I: regarding the immediacy of the moment today, in these postmodern times, one has the impression that the entrepreneurial project is trapped in a temporality of emergence, which prevents it from living up to a future that unfolds over the long term.

JPB: more than in confrontation with emergence, entrepreneurship and the project are trapped in the presentism that characterizes postmodernity and, in its two most dominant forms, urgency and immediacy. These two forms of presentism have destabilizing effects on a project that requires not a short but a longer time frame, as in an entrepreneurial project, where the central objective is creativity.

Alongside these two problematic temporalities of urgency and immediacy that have invaded postmodern spaces, another presentist temporality of emergence currently prevails and casts its ambivalent shadow, sometimes perversely, sometimes protectively, upon the entrepreneurial project: the event-based temporality. It could also be seen as a variant of emergence, since, given the importance of communication in postmodernity, the entrepreneurial project is continually confronted with the emergence of events, sometimes an event carrying a disruptive uncertainty and other times an event generating a positive surprise. This unforeseen event will therefore have continually contrasting contours and hence be better regulated in the presence of an entrepreneurial project. In the absence of 
such a project, entrepreneurship will be thrown back on itself, reduced to develop one or the other form of bricolage or improvisation to both ward off the event and think about its own future.

\section{Entrepreneurship, bricolage, improvisation and creativity}

I: Insofar as both entrepreneurship and the project are creative, how do they rely on bricolage and improvisation?

JPB: bricolage and improvisation, when practiced as part of a project, are forms of creativity. Yet they are much more fragile and vulnerable to the extent that they depend upon the situation of a given moment, and so are unable to provide themselves the means of anticipating a more remote future. The action-based logic that is characteristic of every involvement in a project is concerned with achieving the goals it has set for itself in an environment perceived to be complex. To that end, the project's ability to anticipate plays an essential role in allowing action to prevent and manage gaps, and therefore unforeseen events that slip between the two phases of design and realization that structure any project of action.

Of course, bricolage and improvisation will, each in its own way, help to regulate these differences between the design and realization of a project, allowing it to remain focused on its objectives. What characterizes improvisation is that it always presupposes a prior, already-lived experience on the basis of which it will be able to stage its work. You cannot improvise on something about which you are not familiar, or not without high risk: for improvisation is made possible and beneficial by the fact that it calls on a past that it works to reconfigure. Bricolage is another form of creation in the present moment, a kind of trial and error, aided by a modicum of chance, in its generating of solutions to momentary difficulties. In short, improvisation and bricolage can, temporarily, support the project and stabilize it, even make it more flexible; but left to their own devices, they will quickly get lost in one or another form of distraction.

I: Does this mean that if we nurture creativity through improvisation, we render the entrepreneurial project more flexible?

JPB: the longer the improvisation lasts, the more it will weaken the project, risking its ultimate success. Moreover, the more such improvisation will be deprived of situational opportunities, the more the improvisation itself is weakened. In any case, a too large and prolonged place left to improvisation in the entrepreneurial project will compromise the consistency of the latter.

I: But couldn't improvisation also help a project temporarily adapt to a new situation?

JPB: Yes, of course! Improvisation can provide a kind of regulation, however only temporarily, and on the basis of the kinds of past experience that makes the improvisation possible.

I: What is the form of creativity that would give longevity to entrepreneurship and where does creation remain part of the initial project?

JPB: entrepreneurship benefits from developing creativity that is open to the situation and its futures, and to the opportunities, constraints and resistances to which the project is subject. This creativity must also remain attentive to the positioning and diversity of the stakeholders.

I: And what about the bricolage practice within a project?

JPB: bricolage is something else entirely. We engage in a process of trial and error, in the present moment. We give this a try, and then that, until we find what works. So instead of looking outside for an elaborate device to solve a problem, I do it myself. Thus, there is an element of chance in bricolage. As with improvisation, if we prolong the bricolage process too long, we will weaken the project, though for different reasons. In improvisation, because I rely on the past, I am not paying enough attention to the current situation, which can become radically out of step with my practice. In bricolage, on the other hand, I am actively looking for the right solution, taking temporary and parcelled up initiatives, until eventually, I am forced to take a step back and embrace the situation as a whole from a much broader and more critical perspective. 
IJMPB

12,1

\section{Entrepreneurship and project management}

I: Is the entrepreneurial pool today bound by the same kinds of constraining formats as project management currently is?

JPB: entrepreneurship, first of all, is an uncertain term, both old and new. It is old in that it is semantically derived from the enterprise and its organizational activity. It is new in the desire expressed by an actor-author to want to testify to his ability to undertake in a postmodern society marked by a persistent employment crises and endemic and structural unemployment, due partly to a shortage of jobs resulting from the increasing influence of artificial intelligence on professional activities. The concepts of enterprise, the entrepreneur and above all entrepreneurship are today enjoying a certain success, both in the economic sphere of small- and medium-sized enterprises and in the societal spheres of micro-enterprising, where self-starter sorts of entrepreneurs seem eager to "create their own job.”

Undoubtedly, what these different uses of entrepreneurship have in common is that they underscore the creative posture of the entrepreneur who intends, by his implication and motivation, to give meaning to the activity of his entrepreneurial project. However, relatively little work has been done on this motivation of the entrepreneurial pool of self-employed persons wanting to be entrepreneurial. Entrepreneurship is still a relatively new economic and societal sector. It is still a new type of project that, still largely unknown, must be distinguished, as we have seen, from both project management and the enterprise project.

I: that's why in project management, we need to remember that the objects themselves move. We might say that the very purpose of the project lives several different lives over time. It is not a reified object.

JPB: what the project produces is not a reified object. On the contrary, it produces a prototype, that is to say, an original, singular object. The prototype it produces though does have the possibility of being reified over the course of its serialized production. This is where we depart from a project approach. Indeed, the object created by the project is always that of the prototype, and therefore never the product of repetitive work but the result of a singular approach. From this point of view, digital postmodernity, more so than industrial modernity, is led to work on prototypes rather than on serial objects. This also happens to be in line with customer demand, which seeks uniqueness and differentiation. This does not prevent prototypes from subsequently giving rise to a mass production, of which the history of industrial production can provide many examples.

To summarize, entrepreneurship certainly depends on the situation in which it takes place for the emergence of its possibilities and opportunities. However, in order for there to even be a project, it is essential that these possibilities and opportunities be seized by the intentionality of an actor-author engaged in a creative process. Entrepreneurship, absent the emergence of clearly identified opportunities and possibilities, is doomed to failure over the very short term. At the same time, entrepreneurship is inseparable from its author, who inhabits and animates it. Indeed, absent that author, or in cases where the author is too bashful, entrepreneurship will soon undergo one form or another of drift or decline. For the entrepreneurial project to be successful, there must be found an intersection, or overlap, of possible emergent opportunities with actors-authors able to grasp and seize those opportunities.

\section{About the entrepreneurial project: project to be completed and interminable project}

I: in the entrepreneurial project, what is fascinating is this idea of an open future, implying an indefinite duration. This is difficult to reconcile with the classic notion of a business project that has a limited time frame, with both a start and end date. The entrepreneurial project, though, emerges from a whole series of generative back-and-forth. What exactly is going on here? 
JPB: these back-and-forths between what the project had previously conceived and what it is now carrying out in practice are essential. They are the methodological hallmark of a project approach and also what might be called the iterativity of the work of conception and implementation. Returning to the contradiction between different kinds of business projects, what earlier I called project(-based) management and entrepreneurial project, we must now add two new ways of distinguishing these two types of project, each with their own legitimacy, namely: the project to be completed and the interminable project.

The entrepreneurial project is of the second type, the interminable project, which is characterized by an action in which the author is involved that has no other purpose than to reorganize, reshuffle or even reorient, in advance either of a predetermined deadline, such as an annual meeting, or as a result of some exceptional situation or crisis that the project is going through. In a way, the motto of the interminable project is the imperative to iterate, as a way to break the continuity that is sooner or later likely anyway to run out of steam. In other words, the question is: How might we return to, or iterate, the fundamentals of the entrepreneurship project, either at regular intervals or in an exceptional moment, in order to again take up or rethink the fundamentals of the project in order to reorient it?

Project(-based) management is part of this family of projects that can only be conceived of through the determination of relatively precise objectives to be achieved within very specific deadlines. This family also includes projects that are to be completed and that are governed by what we call the project cycle that includes a series of structuring steps ranging from an initial situational diagnostic to a concluding evaluation, via the development and actual implementation of the work.

I: the example of the video game industry is very much aligned with the kind of back and forths we are talking about, with its prototype and then alpha and beta versions, all of which allow for adjustments to be made along the way. It resembles an entrepreneurial project, an interminable project.

So maybe compared to what you said at the beginning, the project has finally moved away from a closed to a more open paradigm. It has been made entrepreneurial by its agreeing to move through different trial versions, and by integrating the consumer into the production process.

JPB: absolutely, the prototype is the product of an open project, which gives free reign to uncertainty, whereas a closed project allows itself to be instrumentalized by procedures that misguide creativity at the risk of destroying it even.

\section{Space and time in the entrepreneurial project}

I: you've often said that the project is as much a space as a temporality. And today we see that entrepreneurship is also becoming very much more spatialized in this way, with its makerspaces, fablabs, incubators and shared spaces. Here, too, is there not a way to relate project to entrepreneurship, which is something that becomes increasingly territorialized, increasingly as situated as the project is, and therefore as much a space as a temporality?

JPB: initially the project was essentially spatial, inspired by its original paradigm, the architectural project, as early as in the historical period of the Renaissance. This architectural project aimed at creating a space to inhabit. Since then, without abandoning its spatial attachments, the project has been temporalized, over the short, medium and long term, and become something of our alter-ego, the very thing we cannot live our lives without. However, its spatial attachments cannot be replaced completely, insofar as the project expresses, through the etymology of the term (pro-ject), that art of expelling from ourselves that which we are not indifferent, which is to say, one or another form of concern, throwing, projecting it out in front of ourselves, this expelled pro-ject that remains always a part of ourselves. It is indeed this art of throwing in front of oneself that we find in the two different implications of the French word for design, dessein, namely, dessein (design) and 
IJMPB

12,1

dessin (sketch), which is to say, the mental design (the thought that we project in our mind) and the graphic design (the sketch that we throw down on paper). The Italians, from the Renaissance onward, have been using two different terms, disegno interno and disegno externo, for what the English fused into the single formulation design. Certainly, with the advent of modernity, and especially since the enlightenment, we have temporalized the project, sometimes even to excess, having gone so far as even to erase its spatial attachments and privilege its temporal dimensions, as in the development project, event project or career project; indeed, as in any of the variety of those projects of ours that have various deadlines.

Without wishing to impose any sort of competition between time and space, we must recognize that any project is deployed through the intermediate of coordinates that are always and simultaneously spatial and temporal. Hence, the same applies, among others, to the entrepreneurial project. It is within a space still to be identified that the entrepreneurial initiative will take place in a free or determined time frame. However, if I fail to become aware of this space still to be recognized and this time to be tamed, or cognizant of the specific opportunities and constraints that each involve, I will make it difficult for my project to exist.

I: the "entre-" of entrepreneurship, meaning "between" but rhyming in French with "antre," a cave, is a space. And the "-prendre" of entrepreneurship, which in French is the verb "to take" refers to possession. Thus, entre-preneurship is the taking possession of an intermediary space.

JPB: the "entre" is indeed an intermediate space, a space of mediation, of transition, of creation. Yet "enter" is also a time, a measure of interval duration, the guarantor of freedom and a zone of uncertainty in relation to the precision demanded by its very contemporary and tyrannical competitor: immediacy.

\section{From the author of the project to the self-employed person, through the injunction to autonomy}

I: Can we have an entrepreneurial project without an author?

JPB: there is no more project without author than there is smoke without fire! From this point of view, the project, embodied by an author, differs from the program with which it is, unfortunately, often confused. The program is composed of injunctions ordered by an institution. It can be likened to a public order, and is impersonal insofar as it is the institution that speaks through it. On the contrary, the project is a personalized, individual or collective initiative; it is always designated and signed. It is therefore important in a project to distinguish clearly between the author and the actor. If the actor participates in the elaboration and implementation of said project, and provided different forms of status according to his involvement, either as a cooperator or as a confrontational, distant or even critical participant, the actor does not directly assume responsibility for this project. The actor cannot, therefore, be the guarantor either of the values on which the project is based or the strategies that guide it, or of the choice of the means taken to implement it or the momentary results obtained. There is thus inevitably a gap between the author of the project and the actors associated with it, or the various stakeholders, for that matter, who contribute intermittently to its implementation, according to their own status and skills.

To sum up then, in any project, and short of any interim shifting of roles that always winds up causing problems, the author is central and the actors are peripheral.

With this distinction between author and actor clarified, it is important to question: How one becomes the author of an entrepreneurial project? In the enterprise project, the author is inevitably embodied by a collective led or regulated by upper management; yet when it comes to an entrepreneurial project, the author inserts himself into an individual or collective actor role. In the latter case, given the evolution of the entrepreneurial project over 
time and the weight that a functioning collective can ultimately represent, one of the actors often tends to have a leadership role, in favor of this or that event. However, some collectives, on the other hand, when active in a project know how to persist over time.

The entrepreneurial project can also inspire to engage in individual adventures and thus tend to initiate a much more individualized approach. Indeed, the enterprise project requires concerning oneself with the collective, for example, through an appropriate participation mechanism. For example, an enterprise project that becomes too hierarchical, authoritarian or dependent on the enterprise's directors or administrators condemns itself to inefficiency. These observations could also apply to project management; it becomes inoperative if the project engineer does not take into account his project team. On the contrary, the entrepreneurial project tends to focus on the initiator-entrepreneur without excluding other stakeholders. But one could also envisage the entrepreneurial project being led by a couple of co-opted actors, or even a small group of three to five actors.

I: if we look at the work on entrepreneurship over the past 20 or 30 years, it is precisely because it challenges the heroic figure of the entrepreneur and emphasizes, in particular, that the entrepreneur is an isolated individual who manages to overcome challenges against all odds. Indeed, one of the major criticisms of the entrepreneurial field today is that it has built everything on the myth of a single, desocialized individual who is somehow "alone against the rest of the world." As a result, current work is more interested in societal forms of entrepreneurialism, such as entrepreneurial teams.

JPB: but entrepreneurship, which can be likened to enterprise creation, aims to promote a creation that endures over time; in other words, it targets not only the launch of the creation. However, for there to be a lasting creation, authors must be put in a position to take responsibility for their shared project. Work collectives wear out over time, which will generate inertia to challenge the entrepreneurial logic if solitary entrepreneurs do not regain control on a temporary or longer term basis. That's why entrepreneurship finds its natural habitat in more personalized groups, such as very small enterprises and even small- and medium-sized enterprises - but not large enterprises.

Moreover, entrepreneurship does not only have an economic dimension. Nowadays, it has increasingly taken on a social dimension in a chaotic labor market that is threatened by unemployment and where people connect with one another in their search for work, integration or career changes. Entrepreneurship in its social dimension also concerns these people, who are in need of recognition, who might have a taste for a particular professional adventure or hope to test their sense of responsibility, or who seek to assume the role of authors and guarantors of achievements that bear the mark of their own initiative. The development of self-employment over the last ten years is a good example of the individual and social dimension of entrepreneurship.

I: we have one last question that diverges a bit but that is nevertheless linked to the question of the author. In today's discourses, individuals who are employed or looking for work are enjoined to undertake (entreprendre), to put themselves out there, and to become the actors and authors of what they do. This engenders a dissolution of forms of solidarity. The collective is dissolved by the injunction to shoulder the project; the individual is managed as the author of his own enterprise. In the end, the more we talk about projects, the less we create or implement them. And the more we enjoin people to undertake and put themselves out there, giving them autonomy, the more but we compel them to shoulder the burden of the entire organization.

JPB: the autonomy that goes hand in hand with the project is today being effectively abused. This autonomy has become ambiguous, and in this respect it is a hallmark of the current times that we call postmodern. In modernity, this autonomy was authentically an autonomy of "liberation"; it was a question of liberating oneself from constraining situations, from the confining traditions that imposed a certain way of thinking and acting. 
IJMPB

12,1

112

This modern autonomy of liberation, resulting from the Enlightenment, was hailed by the philosophers of the time in response to the existential question of one's capability to feel free. Emmanuel Kant, for example, questioned himself, by questioning his environment in the 1780 s to $90 \mathrm{~s}$, with his essay “Answering the Question: What is Enlightenment?" In his response, he placed great emphasis on the Latin adage Sapere aude!, in other words, "Dare to know!" or "Dare to be autonomous and think for yourself, liberate yourself." His famous response that encouraged autonomy and called on one to "liberate yourself, yourself" has lived on until today. Across all industrialized nations, a desire to liberate oneself of a past that imposed its rules and proscriptions was quite pronounced in the 1960s and 1970s, for example, reaching a peak in 1968. This desire for liberation also led many to resurrect thoughts and actions inherited from ancestral traditions that appeared to have become obsolete.

This desire for autonomy persists, yet has been undermined by the rapid advent of postmodernity in the years 1975-1980. It was also accompanied by the employment and labor crisis, the rise of structural unemployment, a certain impoverishment of workers and their families, as well as the increasing instability of couples and the growing trend of single parenthood, together bringing about many situations of existential and social dependence likely to generate forms of vulnerability. Then, in the face of these different variants of precariousness, the institutions tried to promote another form of autonomy, namely, imposed autonomy, a remedy intended to remove many citizens who had been (or felt to have been) downgraded from the state of dependence in which they found themselves, a dependence which, in passing, was considered too costly for society because it engendered inertia and passivity. This imposed autonomy seeks to oblige the individual to free himself, by himself, from the state of subjugation and without necessarily having the desire to do so. Citizens are summoned through the granting of compensatory assistance to become free, to master their autonomy, be it a young person deprived of social and professional integration or an elderly person seeking care from the community. The "be autonomous!" then becomes synonymous with "take charge of yourself and we will help you."

We are therefore faced today with two contrasting, even conflicting, forms of autonomy that seek to coexist socially and tolerate each other or, as is more often the case, ignore one another:

- The autonomy through the liberation of the person who takes the initiative to acquire the means to free himself from constraints that seem unbearable to him. For example, the intentional termination of a work contract by the employee who feels too determined by his work and his enterprise. This employee takes the risk of facing a professional mobility that seems emancipatory in view of an eroded situation.

- "Autonomy by injunction" compels a person to leave his situation of social and/or economic dependence. For example, the situation of the unemployed person who has reached the limits of his unemployment benefits, and to whom the French unemployment bureau, Pôle Emploi, offers an extension of the assistance he had been granted, in order to finance further training, on the condition that he empower himself to find a job on his own.

Finally, entrepreneurship today is fueled by these two paradoxical, even contradictory autonomies, each of which is as topical as the other. The entrepreneurial project seeks to achieve a liberating autonomy on the part of an actor who aspires to become the author of what he undertakes. At the same time, counsellors engaged in the integration or reintegration of disadvantaged groups impose entrepreneurial autonomy on them in the form of injunctions that they create their own jobs.

Thus, it is in the face of these two contrasting facets of autonomy that we measure the ambiguity of any recourse to "the project." The latter can constitute, depending on the 
situation, an opportunity for emancipation and self-realization as much as an inappropriate and poorly experienced response to a subjugating societal injunction.

It may be interesting to situate each of these two facets in relation to a logic of responsibility, because each mobilizes a specific form of responsibility, although of a very different nature. In the first case, that of the autonomy claimed, we are dealing with a responsibility conjugated to the first person singular, by which the authentic author claims to assume his responsibility to behave as an autonomous actor-author: I am responsible for my professional autonomy. In the second case, that of an imposed responsibility, we are faced with a responsibility articulate in the second person singular, by which the putative author sees himself made, by another or by society at large, responsible for finding himself in a given state of dependence and for achieving on his own a state of greater independence and well-being: You are responsible for your current state of need and therefore for the possibility of you becoming autonomous.

Thus today, in post-industrial societies dominated by a digital culture that emphasizes the principle of servitude by which the service, we purchase is provided by ourselves, autonomy in its ambivalence confronts these two great figures of responsibility. One figure is that of assuming responsibility, which values liberation; and the other, the imposition of autonomy, by which others force us to account for ourselves. Through servitude, I am more autonomous when providing myself with the services I need; however, at the same time, the digital systems that allow me to be autonomous in this way provide me only a very circumscribed form of autonomy.

Olivier Germain School of Business and Management, Université du Québec à Montréal, Montreal, Canada Monique Aubry School of Management, Université du Québec à Montréal, Montreal, Canada, and Marc Bonnemains Department of Management and Technology, School of Business and Management, Université du Québec, Montreal, Canada

\section{References}

Boutinet, J.P. (2004), Vers une société des agendas: Une mutation de temporalités (Toward a society of agendas: A mutation of temporalities), PUF, Paris.

Boutinet, J.P. (2012), Anthropologie du projet (Anthropology of the project), 2nd ed., Quadrige/PUF, Paris.

Garel, G. (2013), "A history of project management models: from pre-models to the standard models", International Journal of Project Management, Vol. 31 No. 5, pp. 663-669.

Scranton, P. (2015), "Projects as a focus for historical analysis: surveying the landscape", History and Technology, Vol. 30 No. 4, pp. 354-373. 